\title{
Longevity of Ceramic Onlays: A Systematic Review
}

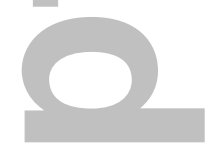

Jaafar Abduo, BDS, DClinDent, PhD, MRACDS (Pros)

Senior Lecturer in Prosthodontics, Convenor of Postgraduate Diploma in Clinical Dentistry

(Implants)

Restorative Section, Melbourne Dental School, Melbourne University

720 Swanston Street, Melbourne, Victoria, Australia, 3010

Raelene Jo Sambrook, BSc, BDSc, DCD (Prosthodontics)

Prosthodontist, Royal Dental Hospital of Melbourne, Victoria, Australia.

720 Swanston Street, Melbourne, Victoria, Australia, 3010

Corresponding author:

Dr Jaafar Abduo

Restorative Section, Melbourne Dental School, Melbourne University

720 Swanston Street, Melbourne, Victoria, Australia 3010

Phone: +61390358998

Fax: $\quad+61393411599$

Email: jaafar.abduo@unimelb.edu.au

\section{Longevity of Ceramic Onlays: A Systematic Review}

\section{ABSTRACT}

Objective: This systematic review aimed to evaluate the longevity of ceramic onlays and identify the factors that influence their survival.

This is the author manuscript accepted for publication and has undergone full peer review but has not been through the copyediting, typesetting, pagination and proofreading process, which may lead to differences between this version and the Version of record. Please cite this article as doi:10.1111/ jerd.12384. 
Materials and Methods: An electronic search was conducted through PubMed (MEDLINE), Google

Scholar and Cochrane Library, up to August 2017. The literature search aimed to retrieve all the clinical studies on the longevity of ceramic onlays. Ceramic onlay was defined as any partial ceramic restoration that covers at least one cusp.

Results: A total of 21 studies met the selection criteria and were deemed suitable for this review. The medium term studies ( 2 - 5 years) indicated a survival rate of $91 \%-100 \%$, and the long term studies (more than 5 years) showed a survival rate of $71 \%$ - 98.5\%. The most common reason of failure was fracture, followed by debonding and caries. The most common patterns of deterioration were loss of margin integrity and discoloration. Onlay longevity can be enhanced if the preparation allows for at least $2 \mathrm{~mm}$ occlusal ceramic thickness and incorporates additional retentive features. Restoring teeth that are non-vital, teeth in a more posterior region, or teeth for patients with parafunctional habits appears to be associated with greater ceramic failure. Fabrication materials and methods, and adhesive bonding system did not seem to influence onlay longevity.

Conclusions: The clinical performance of the ceramic onlay appears acceptable regardless of the follow-up duration. Fracture of the ceramic onlay is the predominant cause of failure, and the most observed form of deterioration was associated with the restoration margin.

\section{CLINICAL SIGNIFICANCE}

Ceramic onlay appears to be a reliable option to restore posterior teeth. The most common pattern of failure is fracture of the ceramic material. The risk of ceramic onlay failure seems to increase if the restored tooth is non-vital and the patient demonstrates parafunctional habits.

Keywords: ceramics; porcelain; longevity, Ceramic Onlay

\section{INTRODUCTION}

Despite the outstanding performance of metal onlays and crowns, ${ }^{1-3}$ their unappealing appearance discourages patients from choosing them. Over the last 20 years, ceramic restorations have become very popular and routinely used in clinical practice. This is further driven by the significant 
developments that have improved the mechanical and optical properties of ceramic materials available for dental restorations. ${ }^{4-6}$ In addition, the development of modern manufacturing techniques has reduced the risk of internal flaw development within the ceramic material, which can further enhance its performance. ${ }^{7,8}$ In parallel to ceramic improvements, there have been advances in adhesive and cementation agents that combine enhanced bonding between the tooth and the ceramic material and ease of use. ${ }^{9-11}$ Consequently, a new range of conservative, tooth-colored and durable restorative options are available. ${ }^{7,8,12,13}$ Contemporary ceramics have been used to restore teeth with inlays, onlays, crowns, or even fixed partial dentures.

The clinical studies have confirmed the successful use of ceramics as dental restorative materials. ${ }^{14,15}$ However, due to the considerable variation, it can be challenging to compare outcomes between studies, materials and restoration types. A number of reviews have collated this information to identify the success and survival of different ceramic restorations and also identify the biological and technical complications that exist. ${ }^{16-20}$ However, to the authors' knowledge, there are no reviews collating the clinical outcomes specifically of ceramic onlay restorations, where the partial ceramic restorations cover all or some of the cusps. The choice to place a ceramic onlay is driven by the need for protecting the tooth with cuspal coverage whilst trying to avoid a traditional crown which has been shown to significantly affect the amount of remaining tooth structure. ${ }^{21,22}$ Detailed analysis on the longevity of ceramic onlay restorations is necessary as it will further confirms the suitability of this conservative option. Subsequently, this qualitative systematic review was undertaken to (1) evaluate the longevity of ceramic onlays and (2) identify the factors that influence the survival of a ceramic onlay.

\section{MATERIALS AND METHODS}

In August 2017, a detailed electronic literature search on ceramic onlay longevity was completed by the two reviewers. The search aimed to retrieve all the clinical studies that evaluated the longevity of ceramic onlays. No year limit was applied. For the purpose of this systematic review, any partial ceramic restoration that covers at least one cusp was considered a ceramic onlay. This may include 
partial crown or overlay restorations. The search was conducted through PubMed (MEDLINE),

Google Scholar and Cochrane Registrar of Controlled Trials. The Boolean operator of the PubMed dataset was implemented to combine the following mix of key words: ('onlay' OR 'partial crown' OR 'partial coverage' OR 'occlusal veneer’ OR 'restoration') AND ('ceramic' OR 'porcelain’) AND ('clinical' OR 'longevity' OR ‘evaluation' OR ‘survival' OR 'performance') AND ('dental' OR 'dentition') NOT ('implant' OR 'bridge' OR 'denture'). The Cochrane Database was searched to retrieve all the articles related to ceramic and porcelain. The Google Scholar search engine was utilized to retrieve additional studies by combining key words such as 'ceramic', 'porcelain', 'onlay', 'partial crown', 'longevity', and 'clinical'. No year limit was applied for the literature search.

The selection of the articles was performed in 3 stages: (1) selection according to the relevance of the title, (2) selection according to the relevance of the abstract, and (3) full text analysis and crossmatching against inclusion criteria (Table 1). After selection of the relevant studies, their bibliographies were searched for additional possible relevant studies. The two reviewers independently screened the retrieved articles, and the agreement level (Cohen's kappa coefficient) was calculated. To reach a consensus, any disagreement was resolved by discussion and referring to the inclusion criteria.

Critical Appraisal Skills Programme (CASP) guidelines were used to evaluate the methodological quality of the selected articles. ${ }^{23}$ The CASP guidelines aim to ensure the study's trustworthiness, importance of the study's results and the study's relevance to the area of practice. This was achieved by asking 12 questions for every article (Table 2). For each guideline question, a score of 1 was given if the answer was yes. If the answer was no or unclear, a score of 0 was given. Therefore, according to this assessment, the highest score that can be achieved is 12 . An overall quality rating for each study was determined as high (12-10), high-moderate (9-8), moderate (7-5), moderate-low (4-3) and low (20). 


\section{RESULTS}

(1)

Literature Search

The electronic search disclosed a total of 2262 articles. Title analysis led to the exclusion of 2202 articles. After reading the abstracts, additional 26 articles were excluded. Therefore, 34 articles were analysed by reading the full-text and cross-matching against the inclusion criteria. The reviewers' agreement had Cohen's kappa value of $92.3 \%$. In situations where multiple follow-up papers were published by the same research group, the most recent paper was selected. This led to the exclusion of an additional 17 articles (Table 3). ${ }^{24-40}$ Reviewing the references of the remaining 17 articles disclosed additional 4 articles suitable for inclusion. Therefore, a total of 21 articles were deemed suitable for inclusion in this review (Table 4)..$^{14,41-60}$ Nine studies (42.9\%) were retrospective and 12 studies $(57.1 \%)$ were prospective. Four of the prospective studies were split mouth studies. ${ }^{48,52,55,58}$ Due to the inevitable heterogeneity of the included studies, whenever possible, the relevant information on failure pattern and deterioration pattern were extracted. Further, the relevant information on the variables that can influence onlay longevity were reported.

\section{Description of Studies}

According to CASP guidelines, the studies' quality scores ranged from 7 to 12 . A total of 16 studies $(76.2 \%)$ had a quality rated as high, 3 studies $(14.3 \%)$ had a quality rating of high-moderate and 2 studies $(9.5 \%)$ were rated to have a moderate quality. The included studies evaluated the longevity of ceramic onlays fabricated from glass-ceramic materials such as feldspathic, castable ceramics (Dicor), leucite-reinforced and lithium disilicate ceramics. Only one study included onlays fabricated from polymer-infiltrated ceramic (Enamic) ${ }^{60}$ The fabrication methods were: sintering, hot pressing, chairside $\mathrm{CAD} / \mathrm{CAM}$ and laboratory $\mathrm{CAD} / \mathrm{CAM}$. In addition to ceramic onlays, some studies included onlays fabricated from different materials such as porcelain fused-to-metal (PFM), indirect composite resin and gold. Further, some studies included ceramic inlay restorations where no cusp coverage was involved. The number of patients included in the studies ranged from 12 to 110 patients. The patients' 
age range was 15 to 81 years. The duration periods of the studies varied from 2 to 15 years.

(1)

Several of the included studies evaluated the effect of the following variables on the ceramic onlay

longevity: ceramic onlay fabrication materials and methods, ${ }^{46,47,55,60}$ vitality of the restored

tooth, ${ }^{14,43,44,54}$ location in the arch, ${ }^{14,43,44,46,47,49,50,53}$ preparation and extension, ${ }^{14,41,44,46,47,49,54,56}$ adhesive and cementation systems, ${ }^{14,43,44,51,53,58}$ and parafunctional activities. ${ }^{14,41,43,47,50}$

All the included studies measured the survival rate. In addition, most of the studies determined the failure patterns, which were extracted and presented in a stacked column graph. Most of the studies monitored the time-dependent onlay degradation patterns in relation to the following criteria: margin integrity, margin discoloration, anatomic form, color match, caries and sensitivity. The majority of the studies implemented a form of universal index (e.g. USPHS or CDA). For each of the degradation criteria, the proportions of successful, surviving and failing restorations were also calculated and presented in stacked column graphs. Success indicates that the variable fulfilled the highest criteria of the author's standard. Survival reflects that the restoration suffered from deterioration that did not necessitate replacement. Failure was considered when the restoration had to be replaced. In situations where the studies included deterioration outcomes at different periods of the study, the deterioration outcome proportions in each evaluation period were calculated.

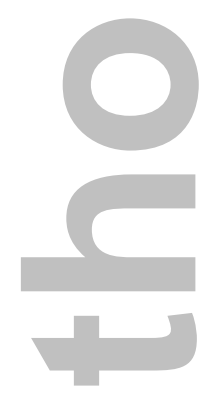

\section{Outcome}

\section{A: Onlay Longevity/Survival}

According to the medium-term studies ( 2 - 5 years) the survival rate had a range of $91 \%-100 \% .{ }^{44-}$ 46,48,49,51,53,54,56,57,59,60 The longer term studies (more than 5 years) generally indicated a reduced 
survival rate $(71 \%-98.5 \%){ }^{14,41-43,47,50,52,55,58}$ The causes of ceramic onlay failure were grouped as onlay fracture, debonding (loss of retention), caries and other causes such as endodontic complications, periodontal complications and extraction of the restored tooth (Figure 1).

By far, the most frequently reported failure pattern was fracture of the onlay and/or the tooth, which was observed in 16 studies $(76.2 \%){ }^{14,41-44,47,49-52,54-56,58-60}$ The fracture percentage of all the failures ranged from $29.1 \%-83.3 \%$. In fact, some studies found onlay fracture as the only failure pattern. ${ }^{42,50,51,54,55}$ The second most common pattern of failure was debonding, which was reported by 9 studies $(42.9 \%)$. $^{43,44,47,49,52,56-58,60}$ The percentage of debonding ranged from $12.0 \%$ to $60.0 \%$ of all failures. The third cause of onlay failure was caries and it was reported by 6 studies $(28.6 \%)$ (incidence of $6.3 \%$ to $40.0 \%$ of all failures)..$^{14,43,44,57,58,60}$

\section{B: Onlay Deterioration}

Regardless of the onlay restorative material and technique, there was a consistent and time-dependent deterioration of the onlays. The commonly observed deterioration patterns were related to margin integrity, margin discoloration, surface roughness, color match and anatomical form.

The most frequent form of deterioration was associated with margin quality (integrity and discoloration). Fourteen studies (66.7\%) reported deterioration of margin integrity (adaptation) in the range of $6.9 \%$ to $86.7 \%$ (Figure 2). ${ }^{41,43,44,48-53,55,57-60}$ It appears that even at baseline, most of the studies reported minor deficiencies of the margin integrity. As the duration of service increased, the success of margin integrity was markedly reduced. However, the prevalence of unacceptable margin integrity occurred in $0 \%-17.8 \%$ of the onlays. Thus, although the margin integrity of ceramic onlays is likely to deteriorate, the prevalence of unacceptable margin integrity was low.

The second most frequent form of deterioration was margin discoloration and this was reported by 13 studies (61.9\%). ${ }^{42-44,48,49,51-53,55,57-60}$ Relatively high levels of margin discoloration were documented 
(ranging from $5.0 \%$ to $88.2 \%$ of the restorations) (Figure 3). However, the prevalence of unacceptable margin discoloration was generally low $(0 \%$ to $0.5 \%)$, except in one study that reported a $44.7 \%$ incidence of unacceptable margin discoloration after 6.5 years. ${ }^{58}$

Onlay color match, surface roughness and contour deteriorations were less prevalent. Eleven studies (52.4\%) observed deficiency in onlay color match, ${ }^{43,44,48-51,53,55,57,59,60}$ that was in the range of $0 \%$ to $75.0 \%$ of the onlays (Figure 4). However, unacceptable color match was reported to occur in up to $4.0 \%$ of the onlays. Increase in surface roughness occurred in 12 studies (57.1\%) and affected up to $4.0 \%$ to $87.5 \%$ of the ceramic onlays (Figure 5). ${ }^{43,44,48-50,52,53,55-59}$ In general, the rate of unacceptable surface roughness was low ( $0 \%$ to $10.4 \%$ of onlays). Contour or anatomic form was evaluated by 14 studies (66.7\%) (Figure 6), ${ }^{43,44,48-53,55-60}$ and limitations in the contour were found to be in the range of $0 \%$ to $60.0 \%$ on the onlays. The unacceptable contour rate was low and in the range of $0 \%$ to $16.2 \%$. It appears that there were considerable variations in the color match, surface roughness and contour among the studies, even at baseline. Nevertheless, the low incidence of onlay failure due to these variables indicates that they are not major limitations of ceramic onlays.

On the contrary, few papers (23.8\%) reviewed the occurrence of hypersensitivity, which was more prevalent at baseline (Figure 7)..$^{45,51,52,58,59}$ However, the studies consistently reported reduction and disappearance of the hypersensitivity, which indicates that the hypersensitivity after onlay cementation is of a transient nature.

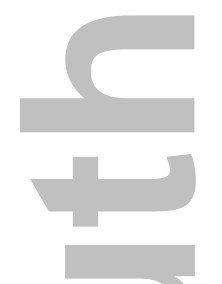

\section{C: Factors Influencing Onlay Outcome}

Preparation and extension: Three studies (14.3\%) evaluated the effect of preparation variables on onlays longevity. ${ }^{43,47,54}$ Smales and Etemadi found no clear influence of preparation thickness (2.1 $3.2 \mathrm{~mm}$ floor depth reduction, and 1.6 - $2.6 \mathrm{~mm}$ working cusp reduction) and taper on fracture of 
molar felspathic onlays. ${ }^{47}$ van Dijken and Hasselrot evaluated 4 preparation designs for leucitereinforced ceramic: (1) partial coverage with no shoulder, (2) partial coverage with minimal retentive features (shoulder or chamfer), (3) full coverage with minimal retentive features (shoulder or chamfer addition) and (4) endodontically treated teeth with no retention (no post or core). ${ }^{43}$ The $4^{\text {th }}$ group had the greatest failure rate $(37 \%)$, followed by the $1^{\text {st }}$ group $(34.5 \%)$. The $2^{\text {nd }}(18.2 \%)$ and $3^{\text {rd }}(22.6 \%)$ groups were relatively similar and had the most superior outcome. Their results indicated that incorporation of retentive features within the preparation may reduce the failure of onlay restorations. ${ }^{43}$ Murgueitio and Brenal evaluated the effect of 3 leucite-reinforced onlay occlusal thicknesses: thin ( $1 \mathrm{~mm}$ to $1.4 \mathrm{~mm})$, medium ( $1.5 \mathrm{~mm}$ to $1.9 \mathrm{~mm}$ ), and thick ( $2 \mathrm{~mm}$ or more). ${ }^{54}$ They found that increased leucite-reinforced ceramic onlay thickness reduced the probability of failures, and $85.7 \%$ of the fractures were for onlays with thicknesses less than $2 \mathrm{~mm}$.

Five studies (23.8\%) included comparisons between ceramic onlays and ceramic inlays. Felden et al. found significantly lower survival probability for onlays (cast, pressed, sintered and milled) than inlays over a 7 years period. ${ }^{42}$ However, they attributed the failures to the inclusion of weak ceramic material such as castable ceramic. On the other hand, 3 studies found that onlays exhibited better longevity than inlays. ${ }^{46,49,56}$ Over 5 years, Arnelund et al. reported an insignificantly higher tendency of failure for inlays than onlays (pressed leucite-reinforced or sintered feldspathic). ${ }^{46}$ Likewise, after 4 years, Naeselius et al., and Klink and Huettig had found significantly better survival for onlays than inlays for pressed leucite-reinforced and feldspathic ceramics respectively. ${ }^{49,56}$ However, after 8.5 years, Beier et al. had found no significant difference between onlays and inlays fabricated from feldspathic ceramic. ${ }^{14}$ 1.

Therefore, it appears from the available studies, ceramic onlay longevity, specifically fabricated from leucite-reinforced, may be enhanced by providing sufficient occlusal thickness of at least $2 \mathrm{~mm}$. Retentive features appear to have a positive effect. There is tendency for the ceramic onlays to be associated with a better clinical outcome than inlays. However, more standardized studies are needed to confirm these outcomes. 
Fabrication materials and methods: Four studies (19.1\%) compared different materials and methods for fabricating the ceramic onlays. ${ }^{42,46,55,60}$ After evaluating cast, pressed, milled and sintered ceramics, Felden et al. found $92.9 \%$ of the fractures occurred in restorations fabricated from cast ceramics over 7 years. ${ }^{42}$ Over 5 years, Arnelund et al. found no difference in the clinical performance of sintered feldspathic ceramic and pressed leucite-reinforced ceramic. ${ }^{46}$ After 7 years, Guess et al. found milled leucite-reinforced ceramic and pressed lithium disilicate ceramic onlays to have similar reliability. ${ }^{55}$ Interestingly, milled inlays exhibited increased surface roughness and a more deficient color match, which may be attributed to the milling process. A 3 years study indicated that onlays fabricated from chairside CAD/CAM feldspathic and polymer-infiltrated ceramics have similar clinical outcome. ${ }^{60}$ Therefore, with the exception of cast ceramic onlays which are not applicable to contemporary dental practice, none of the available studies reported systemic superiority of any material or fabrication method. This is further supported by the rest of the studies that indicated the feasibility of ceramic onlays regardless of the material used and the method of fabrication. Further, the evaluated CAD/CAM systems appear to provide an acceptable outcome.

Three studies (14.3\%) compared the longevity of ceramic onlays against alternative onlay materials. ${ }^{47,48,52}$ Smales and Etimadi compared feldspathic ceramic onlays and PFM onlays. In general, the two materials demonstrated similar clinical performance over the 6 years period. ${ }^{47}$ Kaytan et al. compared ceramic onlays (pressed leucite-reinforced) and composite resin onlays over 2 years. ${ }^{48}$

Overall, the two materials were similar, except for the color match, which was superior for the ceramic onlays. Over 5.5 years, Federlin et al. compared ceramic onlays against gold onlays. They found that although the survival was similar for the 2 onlay materials, ceramic onlays had inferior stability of margin integrity, margin discoloration and anatomic form. ${ }^{52}$

Therefore, studies to date suggest there is no indication that one ceramic material performs better than another, and the fabrication methods appear to minimally influence the ceramic onlay performance.

After comparing ceramic onlay materials to indirect composite or cast gold restorations, it appears 
that the survival rate is similar. However, the gold onlays tend to be more resistant to deterioration, whilst the indirect composite onlays tend to be inferior to ceramic onlays.

(2)

Restoration location: Six studies $(28.6 \%)$ reported the implication of restoration location on longevity. ${ }^{14,46,47,49,50,54,59}$ Arnelund et al. indicated that molar onlays were 4 times more likely to fail than premolar onlays. ${ }^{46}$ Similarly, the studies by Smales and Etemadi, and Otto and Schneider found molar onlays had 3 times more fracture than premolar onlays. ${ }^{47,50}$ The other studies found that failures occurred on molars only. ${ }^{49,54,59}$ In one of these studies, ceramic onlays on $2^{\text {nd }}$ molars were 5 times more susceptible to fail than those on $1^{\text {st }}$ molars. ${ }^{54}$ On the other hand, Beier et al. did not report significant difference of the survival for ceramic onlays on premolars and molars. ${ }^{14}$

Bonding and cementation agents: Although several adhesives and cementation agents were implemented, overall, the studies did not clearly disclose a preference for one system over another. Five studies (23.8\%) evaluated the impact of bonding and cementation agents on ceramic onlays longevity. ${ }^{43,44,51,53,58}$ Two studies found no difference between dual-cured and self-cured composite cements. ${ }^{43,44}$ Similarly, Barnes et al. and Atali et al. found no difference between different dual-cured composite cements. ${ }^{51,53}$ In a cross mouth study, Baader et al. evaluated 2 different cementation protocols using self-adhesive resin cementation material. Half of the onlays were cemented with selective enamel etching and the other half were cemented without selective enamel etching. ${ }^{58}$ Both of the cementation methods experienced deterioration over time with respect to margin integrity and margin discoloration. They observed a significantly higher survival rate after selective etching than without, which led them to recommending selective etching prior to the use of self-adhesive resin cement when covering multiple cusps with reduced retention and tooth structure.

Tooth vitality: Four studies (19.1\%) reported the outcome of ceramic onlays on vital and non-vital teeth. ${ }^{14,43,44,54}$ The consensus of the studies is that vital teeth have a more favourable outcome and were less likely to fail than non-vital teeth. Nevertheless, 3 studies were conducted solely on non-vital 
teeth and the authors reported an acceptable outcome..$^{53,57,60}$

-

Parafunct

Parafunctional habits: 4 studies (19.1\%) clearly stated that they excluded patients with parafunctional habits $^{45,48,55,57}$ and several studies (57.1\%) did not provide any specification. ${ }^{41,44,46,49,51-54,56,58-60}$ A total of 5 studies (23.8\%) reported the effect of parafunctional habits on the longevity of onlays, ${ }^{14,42,43,47,50}$ and 4 of them showed a negative effect of parafunctional habits on onlay longevity. Felden et al. found all the fractures occurred in patients with signs of attrition. ${ }^{42}$ Smales and Etemadi, and van Dijken and Hasselrot reported a greater chance for onlays failure for patients with parafunctional habits ${ }^{43,47}$. Some studies found that patients with multiple fractures had bruxism. ${ }^{50,59}$ On the contrary, Beier et al. indicated no greater risk for patients with bruxism. ${ }^{14}$

\section{DISCUSSION}

\section{Ceramic Onlay Survival}

This review confirms that ceramic onlays have an acceptable medium term survival $(91 \%-100 \%)$ and long term survival (71\% - 98.5\%). This finding is consistent with other reviews assessing survival of ceramic restorations. ${ }^{16-19}$ A literature review by El-Mowafy and Brochu identified that survival rates for ceramic restorations ranged from $96 \%$ at 4.5 years to $91 \%$ at 7 years. ${ }^{16}$ Pieger et al. demonstrated that ceramic crowns had a cumulative survival rate of $97.8 \%$ at 5 years, and $96.7 \%$ at 10 years. ${ }^{19}$ More recently, a systematic review by Morimoto et al. showed that the estimated survival rate for the ceramic restorations was $95 \%$ at 5 years and $91 \%$ at 10 years. ${ }^{18}$ Similar to this study, these reviews on ceramic restorations consistently reported that fracture is the most frequent type of ceramic restoration failure, ${ }^{16-19}$ which can be attributed to ceramic vulnerability to fatigue and crack propagation from internal or external surfaces. ${ }^{7}$

The second most common cause for ceramic onlay failure is debonding which reflects failure at the cementation interface. Although the use of adhesives is commonplace in the modern dental practice, 
the procedure for ceramic bonding remains technique sensitive. ${ }^{9,43}$ Factors that complicate ceramic adhesion include cement manipulation and adherence to bonding protocol, moisture control and etching..$^{58}$ This is even more important for onlays due to the generally less retentive preparation and the greater reliance on the adhesive bonding to retain the restoration. However, from the studies assessed, due to the number of different types of adhesives, cements, treatments of the ceramic surface and variable isolation techniques used, it was impossible to observe a relationship between the cementation procedure and debonding. It was noted that, in one study, the involved clinicians had a different failure rate of ceramic restorations, which may be attributed to different cementation techniques and clinical experience. ${ }^{44}$

In comparison with other indirect onlay restorations (PFM, composite and gold), the limited data illustrates that ceramic onlays yield a generally comparable survival outcome. ${ }^{47,48,52}$ While the longevity of ceramic onlays appear to be similar to composite onlays, ceramic onlays have the advantage of being more color stable. ${ }^{48}$ Such observations can be due to the stability of ceramic material in the oral environment as opposed to composite resin material which is more prone to surface wear and discoloration. ${ }^{17,48}$ On the other hand, according to the present review, ceramic onlays have inferior stability (anatomic form, margin integrity and discoloration) to gold onlays. ${ }^{52}$ Earlier published studies assessing survival of gold onlays indicated similar survival to the observed outcome of ceramic onlays. The 10 year survival rates for gold onlays have been reported as $96.1 \%^{1}, 94.5 \%{ }^{2}$ and $97 \%{ }^{3}$ However, the failure pattern for gold onlay is somewhat different from ceramic onlays. Studer et al. identified in their study that the predominant reasons for failure of the gold onlays being secondary caries and loss of retention. ${ }^{1}$ These results for gold onlays, when compared with the results from this review, illustrate that onlay restorations constructed from ceramic are at risk of failing by nature of the ceramic material itself. Due to the vulnerability of ceramic onlays to fracture, it is reasonable for the clinician to consider factors or modify their technique and selection criteria to enhance the outcome of ceramic onlays, which will be discussed later.

\section{Ceramic Onlay Deterioration}


The reviewed studies revealed time dependent degradation of the ceramic onlays that was more noticeable in the longer term studies. The most common form of deterioration was associated with the restoration margins. ${ }^{41,43-45,48-53,55,57,58}$ Margin integrity and discoloration are most likely influenced by the intimacy of margin fit of the ceramic restoration, and mechanical and chemical degradation of the adhesive cement. Such problems are further accentuated if there is inaccuracy in the margin fit of the ceramic restoration, or failure to seat the restoration due to the viscosity of composite cements. A laboratory investigation indicated a relationship exists between the width of the margin gap and the depth of margin deficiency. ${ }^{10}$ Further, an SEM analysis of cemented inlays reported that the wider gap between the ceramic and tooth structure is associated with increased wear of the cementation composite and subsequent development of a margin deficiency. ${ }^{11}$ Further, a wider gap will increase the portion of cement that is subjected to water sorption and eventual hydrolysis and plasticising of the polymer contents. ${ }^{43}$ In effect, loss of the resin cement at the tooth-restoration interface creates an irregular surface that is susceptible to staining. Whilst this pattern of deterioration did not influence the survival of ceramic onlays, it may have important clinical consequences. In particular, if a patient is driven for an esthetic restoration, staining at the margin may compromise the patient's acceptance of the restoration in the long run.

\section{Factors Influencing Ceramic Onlay Longevity}

Despite the variations in ceramic materials composition and production methods, no relationship was evident between ceramic material and fabrication method, and ceramic onlay failure rate. ${ }^{42,46,55}$ This systematic review indicates that more modern technologies for manufacturing ceramic onlays, such as chairside and laboratory $\mathrm{CAD} / \mathrm{CAM}$ systems, appear to be comparable to conventional methods for producing ceramic onlays. This observation will most likely continue in the future with further advancement in the precision of digital dentistry. The similarity in the outcome of the onlay restorations regardless of the material and fabrication method can be attributed to the 'strengthening effect' of adhesive bonding of a glass ceramic material. This applies to feldspathic, leucite-reinforced and lithium disilicate ceramics, which can be attributed to adhesive cementation compensating for the 
mechanical differences between the different materials. ${ }^{18}$ Thus, while different ceramics exhibit different mechanical properties, the influence on the clinical performance is less obvious. In addition, the partial coverage nature of the ceramic onlays means the durability of the onlay is attained from the remaining tooth structure and the available enamel that can further enhance the adhesive bonding. On the other hand, no study assessed the outcome of densely sintered ceramics, such as zirconia, for onlay restorations. It would be interesting to see how these alternative ceramic materials with improved mechanical behaviour would compare to the glass-ceramic materials for onlays.

In terms of tooth preparation, it was stated by Murgueitio and Brenal that inadequate occlusal ceramic thickness was associated with onlay fracture. ${ }^{54}$ Occlusal ceramic thickness of at least $2 \mathrm{~mm}$ was reported to reduce the risk of fracture for the glass-ceramic leucite-reinforced onlays, which can be attributed to resistance of flexion and crack propagation. ${ }^{43,54}$ Further, addition of retentive features to the onlay preparation, such as shoulders or chamfers, was reported to enhance the survival of the ceramic onlays. ${ }^{43}$ Such retentive features will increase the bonding interface between the tooth and the ceramic which has the capacity to improve the retention and fracture resistance. Further, the retentive features will provide a defined path of insertion of the onlay which will facilitate seating during cementation and reduce the exposure of the cement at the margin.

\footnotetext{
Whilst a number of studies identified that loss of tooth vitality negatively influenced the survival of ceramic onlays, ${ }^{14,43,44,54}$ it is difficult to conclude that loss of tooth vitality per se is a risk factor for ceramic onlay fracture as other studies indicated acceptable outcomes of ceramic onlays when restoring non-vital teeth. ${ }^{53,57}$ The inferior survival of non-vital teeth may otherwise be attributed to the lack of remaining tooth structure. Subsequently, in comparison to the vital tooth the restored non-vital tooth may have less capacity to support and retain the ceramic restoration. ${ }^{43,54}$
}

An observed pattern from this review is ceramic onlays are prone to failure in a high stress environment such as patients with parafunctional habits/bruxism and restorations on teeth further in the posterior region. Overall there is a perception that bruxism is associated with greater ceramic 
restoration fracture which led some studies to exclude patients with signs of bruxism. ${ }^{45,48,55,57}$ Other

西 studies related ceramic fractures to the patient being a bruxist, evidenced with signs of attrition. ${ }^{14,43,47,50}$ However, in the studies reviewed, it is challenging to know if the ceramic fracture can be attributable directly with bruxism or alternative explanations such as the material used, clinical techniques and ceramic thickness. Further, it is not yet clear if additional clinical considerations should be implemented prior to placing ceramic restorations for patients with bruxism. The location of the onlay restoration within the dental arch has also been considered as a factor that may influence the longevity of a ceramic restoration. In the studies reviewed, despite a higher number of failures on molar teeth compared to premolars, this was not always significant. ${ }^{14,46,47,49,50,54}$ The tendency of greater ceramic onlay failure in the more posterior position in the arch may be attributed to increased occlusal forces on the more posterior teeth. ${ }^{54}$ To overcome the sensitivity of ceramic restorations to heavy occlusal forces, it has been suggested that metallic restorations are more ideal in areas where high occlusal forces are anticipated. ${ }^{13,52}$

Although this systematic review provides updated understanding on ceramic onlays, it suffers from several limitations, mainly the limited number of studies and the heterogeneity of the materials and assessments used. Whilst the majority of the studies implemented a form of universal index (e.g. USPHS or CDA), the reporting of the information differed. One of the reasons behind this variation is the subjectivity in restoration evaluation, inevitable operators' differences and the interrelation between these variables.

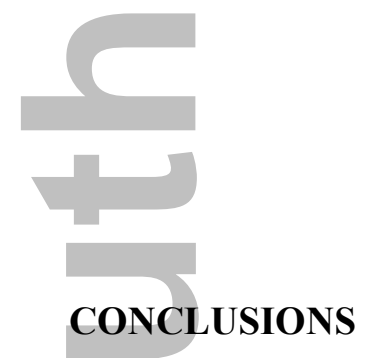

Within the limitations of this study, it can be concluded that regardless of the follow-up duration, ceramic onlay restorations exhibited acceptable clinical outcomes. The most common pattern of failure of a ceramic onlay was fracture, followed by debonding. The most observed form of 
deterioration was associated with margin integrity and discoloration. Tooth preparation, tooth vitality and occlusal force appear to influence ceramic onlay survival. Different modern glass-ceramic materials, manufacturing techniques, and cementation materials have minimal effect on glass ceramic onlay survival. Future clinical research should aim to evaluated more optimised ceramic material and bonding technologies that can overcome the most common patterns of ceramic onlay failure and deterioration. In addition, the clinical studies should be more rigidly designed to isolate the factors that can influence the clinical outcome.

Disclosure Statement: The authors declare no conflict of interest or financial interest with any of the products included in the manuscript.

\section{REFERENCES}

1. Studer SP, Wettstein F, Lehner C, et al. Long-term survival estimates of cast gold inlays and onlays with their analysis of failures. J Oral Rehabil 2000;27:461-72.

2. Bentley C, Drake CW. Longevity of restorations in a dental school clinic. J Dent Educ 1986;50:594-600.

3. Bandlish LK, Mariatos G. Long-term survivals of 'direct-wax' cast gold onlays: a retrospective study in a general dental practice. Br Dent J 2009;207:111-5.

4. Sasse M, Krummel A, Klosa K, Kern M. Influence of restoration thickness and dental bonding surface on the fracture resistance of full-coverage occlusal veneers made from lithium disilicate ceramic. Dent Mater 2015;31:907-15.

5. Homaei E, Farhangdoost K, Tsoi JK, et al. Static and fatigue mechanical behavior of three dental CAD/CAM ceramics. J Mech Behav Biomed Mater 2016;59:304-13.

6. Guess PC, Schultheis S, Wolkewitz M, et al. Influence of preparation design and ceramic thicknesses on fracture resistance and failure modes of premolar partial coverage restorations. J Prosthet Dent 2013;110:264-73. 
7. Kelly JR. Dental ceramics: what is this stuff anyway? J Am Dent Assoc 2008;139 Suppl:4S-7S.

8. Kelly JR, Benetti P. Ceramic materials in dentistry: historical evolution and current practice. Aust Dent J 2011;56:84-96.

9. Mante FK, Ozer F, Walter R, et al. The current state of adhesive dentistry: a guide for clinical practice. Compend Contin Educ Dent 2013;34:2-8.

10. Kawai K, Isenberg BP, Leinfelder KF. Effect of gap dimension on composite resin cement wear. Quintessence Int 1994;25:53-8.

11. Peumans M, Voet M, De Munck J, et al. Four-year clinical evaluation of a self-adhesive luting agent for ceramic inlays. Clin Oral Investig 2013;17:739-50.

12. Thoma DS, Sailer I, Ioannidis A, et al. A systematic review of the survival and complication rates of resin-bonded fixed dental prostheses after a mean observation period of at least 5 years. Clin Oral Implants Res 2017; doi: 10.1111/clr.13007.

13. Raigrodski AJ, Chiche GJ, Potiket N, et al. The efficacy of posterior three-unit zirconium-oxidebased ceramic fixed partial dental prostheses: a prospective clinical pilot study. J Prosthet Dent 2006;96:237-44.

14. Beier US, Kapferer I, Burtscher D, et al. Clinical performance of all-ceramic inlay and onlay restorations in posterior teeth. Int J Prosthodont 2012;25:395-402.

15. Belli R, Petschelt A, Hofner B, et al. Fracture Rates and Lifetime Estimations of CAD/CAM Allceramic Restorations. J Dent Res 2016;95:67-73.

16. El-Mowafy O, Brochu JF. Longevity and clinical performance of IPS-Empress ceramic restorations--a literature review. J Can Dent Assoc 2002;68:233-37.

17. Fron Chabouis H, Smail Faugeron V, Attal JP. Clinical efficacy of composite versus ceramic inlays and onlays: a systematic review. Dent Mater 2013;29:1209-18.

18. Morimoto S, Rebello de Sampaio FB, Braga MM, et al. Survival Rate of Resin and Ceramic Inlays, Onlays, and Overlays: A Systematic Review and Meta-analysis. J Dent Res 2016;95:98594.

19. Pieger S, Salman A, Bidra AS. Clinical outcomes of lithium disilicate single crowns and partial fixed dental prostheses: a systematic review. J Prosthet Dent 2014;112:22-30. 
20. Sailer I, Makarov NA, Thoma DS, et al. All-ceramic or metal-ceramic tooth-supported fixed dental prostheses (FDPs)? A systematic review of the survival and complication rates. Part I: Single crowns (SCs). Dent Mater 2015;31:603-23.

21. Edelhoff D, Sorensen JA. Tooth structure removal associated with various preparation designs for posterior teeth. Int J Periodontics Restorative Dent 2002;22:241-9.

22. Al-Fouzan AF, Tashkandi EA. Volumetric measurements of removed tooth structure associated with various preparation designs. Int J Prosthodont 2013;26:545-8.

23. Critical Appraisal Skills Programme (CASP): Critical Appraisal Checklists. http://wwwcaspuknet/.

24. Federlin M, Manner T, Hiller KA, et al. Two-year clinical performance of cast gold vs ceramic partial crowns. Clin Oral Investig 2006;10:126-33.

25. Federlin M, Wagner J, Manner T, et al. Three-year clinical performance of cast gold vs ceramic partial crowns. Clin Oral Investig 2007;11:345-52.

26. 26. Federlin M, Hiller KA, Schmalz G. Effect of selective enamel etching on clinical performance of CAD/CAM partial ceramic crowns luted with a self-adhesive resin cement. Clin Oral Investig 2014;18:1975-84.

27. Frankenberger R, Petschelt A, Kramer N. Leucite-reinforced glass ceramic inlays and onlays after six years: clinical behavior. Oper Dent 2000;25:459-65.

28. Frankenberger R, Taschner M, Garcia-Godoy F, et al. Leucite-reinforced glass ceramic inlays and onlays after 12 years. J Adhes Dent 2008;10:393-8.

29. Guess PC, Strub JR, Steinhart N, et al. All-ceramic partial coverage restorations--midterm results of a 5-year prospective clinical splitmouth study. J Dent 2009;37:627-37.

30. Kramer N, Frankenberger R, Pelka M, Petschelt A. IPS Empress inlays and onlays after four years--a clinical study. J Dent 1999;27:325-31.

31. Kramer N, Taschner M, Lohbauer U, et al. Totally bonded ceramic inlays and onlays after eight years. J Adhes Dent 2008;10:307-14.

32. Posselt A, Kerschbaum T. Longevity of 2328 chairside Cerec inlays and onlays. Int J Comput Dent 2003;6:231-48. 
33. Santos MJ, Mondelli RF, Navarro MF, et al. Clinical evaluation of ceramic inlays and onlays

fabricated with two systems: five-year follow-up. Oper Dent 2013;38:3-11.

34. Santos MJ, Freitas MC, Azevedo LM, et al. Clinical evaluation of ceramic inlays and onlays

fabricated with two systems: 12-year follow-up. Clin Oral Investig 2016;20:1683-90.

35. Schenke F, Federlin M, Hiller KA, et al. Controlled, prospective, randomized, clinical evaluation of partial ceramic crowns inserted with RelyX Unicem with or without selective enamel etching. 1-year results. Am J Dent 2010;23:240-6.

36. Schenke F, Federlin M, Hiller KA, et al. Controlled, prospective, randomized, clinical evaluation of partial ceramic crowns inserted with RelyX Unicem with or without selective enamel etching. Results after 2 years. Clin Oral Investig 2012;16:451-61.

37. Schulte AG, Vockler A, Reinhardt R. Longevity of ceramic inlays and onlays luted with a solely light-curing composite resin. J Dent 2005;33:433-42.

38. Silva RHBT, Ribeiro APD, Catirze ABCE, et al. Clinical performance of indirect esthetic inlays and onlays for posterior teeth after 40 months. Braz J Oral Sci 2009;8:154-8.

39. Tagtekin DA, Ozyoney G, Yanikoglu F. Two-year clinical evaluation of IPS Empress II ceramic onlays/inlays. Oper Dent 2009;34:369-78.

40. Zimmer S, Gohlich O, Ruttermann S, et al. Long-term survival of Cerec restorations: a 10-year study. Oper Dent 2008;33:484-7.

41. Felden A, Schmalz G, Hiller KA. Retrospective clinical study and survival analysis on partial ceramic crowns: results up to 7 years. Clin Oral Investig 2000;4:199-205.

42. Felden A, Schmalz G, Federlin M, Hiller KA. Retrospective clinical investigation and survival analysis on ceramic inlays and partial ceramic crowns: results up to 7 years. Clin Oral Investig $1998 ; 2: 161-7$.

43. van Dijken JW, Hasselrot L. A prospective 15-year evaluation of extensive dentin-enamel-bonded pressed ceramic coverages. Dent Mater 2010;26:929-39.

44. van Dijken JW, Hasselrot L, Ormin A, Olofsson AL. Restorations with extensive dentin/enamelbonded ceramic coverage. A 5-year follow-up. Eur J Oral Sci 2001;109:222-9. 
45. Barghi N, Berry TG. Clinical evaluation of etched porcelain onlays: a 4-year report. Compend Contin Educ Dent 2002;23:657-64.

46. Arnelund CF, Johansson A, Ericson M, et al. Five-year evaluation of two resin-retained ceramic systems: a retrospective study in a general practice setting. Int J Prosthodont 2004;17:302-6.

47. Smales RJ, Etemadi S. Survival of ceramic onlays placed with and without metal reinforcement. J Prosthet Dent 2004;91:548-53.

48. Kaytan B, Onal B, Pamir T, Tezel H. Clinical evaluation of indirect resin composite and ceramic onlays over a 24-month period. Gen Dent 2005;53:329-34.

49. Naeselius K, Arnelund CF, Molin MK. Clinical evaluation of all-ceramic onlays: a 4-year retrospective study. Int J Prosthodont 2008;21:40-4.

50. Otto T, Schneider D. Long-term clinical results of chairside Cerec CAD/CAM inlays and onlays: a case series. Int J Prosthodont 2008;21:53-9.

51. Barnes D, Gingell JC, George D, et al. Clinical evaluation of an all-ceramic restorative system: a 36-month clinical evaluation. Am J Dent 2010;23:87-92.

52. Federlin M, Hiller KA, Schmalz G. Controlled, prospective clinical split-mouth study of cast gold vs. ceramic partial crowns: 5.5 year results. Am J Dent 2010;23:161-7.

53. Atali PY, Cakmakcioglu O, Topbasi B, et al. IPS Empress onlays luted with two dual-cured resin cements for endodontically treated teeth: a 3-year clinical evaluation. Int J Prosthodont $2011 ; 24: 40-2$

54. Murgueitio R, Bernal G. Three-year clinical follow-up of posterior teeth restored with leucitereinforced ips empress onlays and partial veneer crowns. J Prosthodont 2012;21:340-5.

55. Guess PC, Selz CF, Steinhart YN, et al. Prospective clinical split-mouth study of pressed and CAD/CAM all-ceramic partial-coverage restorations: 7-year results. Int J Prosthodont 2013;26:21-5.

56. Klink A, Huettig F. Complication and survival of Mark II restorations: 4-year clinical follow-up. Int J Prosthodont 2013;26:272-6. 
57. Ozyoney G, Yan Koglu F, Tagtekin D, Hayran O. The efficacy of glass-ceramic onlays in the restoration of morphologically compromised and endodontically treated molars. Int J Prosthodont $2013 ; 26: 230-4$.

58. Baader K, Hiller KA, Buchalla W, et al. Self-adhesive Luting of Partial Ceramic Crowns: Selective Enamel Etching Leads to Higher Survival after 6.5 Years In Vivo. J Adhes Dent 2016;18:69-79.

59. Archibald JJ, Santos GC, Jr., Moraes Coelho Santos MJ. Retrospective clinical evaluation of ceramic onlays placed by dental students. J Prosthet Dent 2017; doi:

10.1016/j.prosdent.2017.07.004.

60. Lu T, Peng L, Xiong F, et al. A 3-year clinical evaluation of endodontically treated posterior teeth restored with two different materials using the CEREC AC chair-side system. J Prosthet Dent 2017; doi: 10.1016/j.prosdent.2017.04.022.
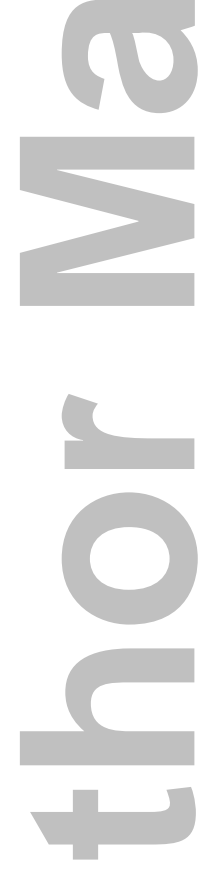

\section{LEGENDS}

TABLE 1. Inclusion criteria

TABLE 2. Critical Appraisal Skills Programme (CASP) guidelines and scoring system

TABLE 3. The excluded studies and the reasons of their exclusion 
TABLE 4. Summary of the included studies

FIGURE 1 Distribution of the failure pattern proportions (\%) from the included studies

FIGURE 2 Margin integrity

FIGURE 3 Margin discoloration

FIGURE 4 Color match

FIGURE 5 Surface roughness

FIGURE 6 Anatomic form

FIGURE 7 Hypersensitivity
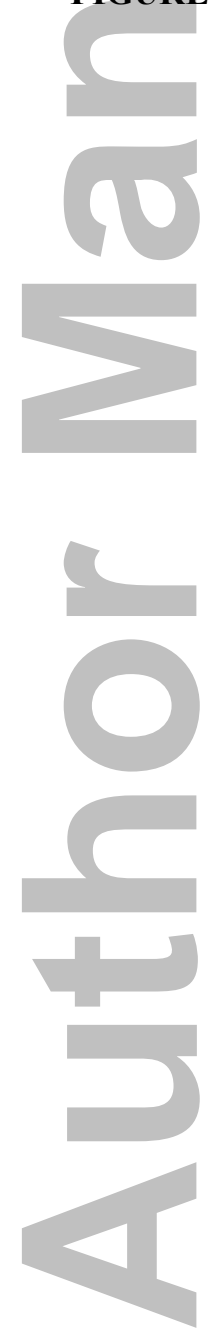


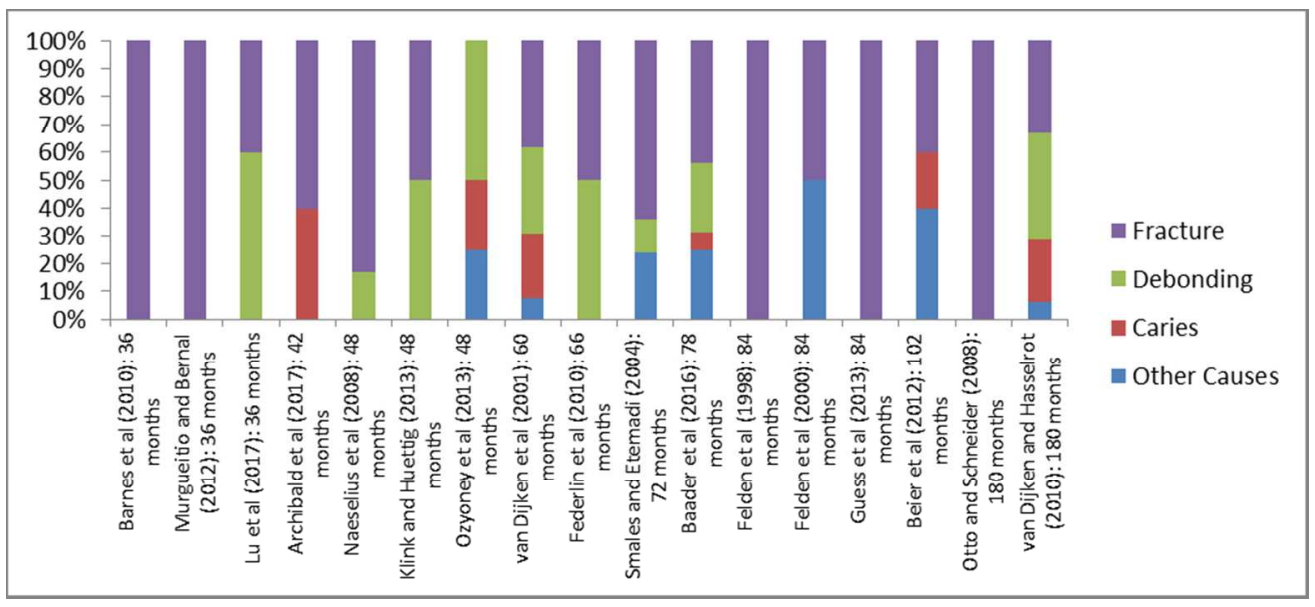

Distribution of the failure pattern proportions (\%) from the included studies $169 \times 76 \mathrm{~mm}(150 \times 150 \mathrm{DPI})$ 


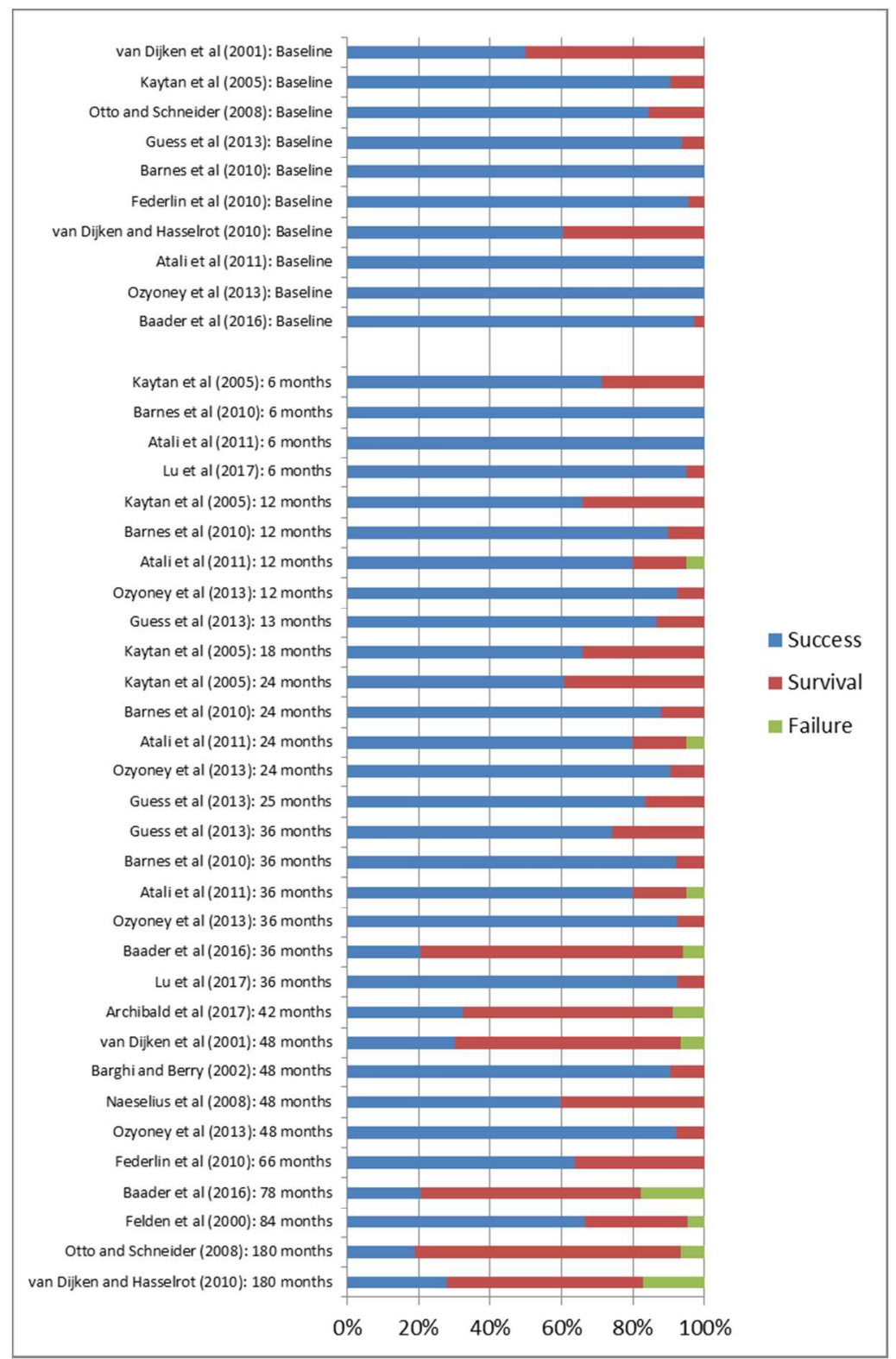

Margin integrity

$130 \times 200 \mathrm{~mm}(150 \times 150$ DPI $)$ 


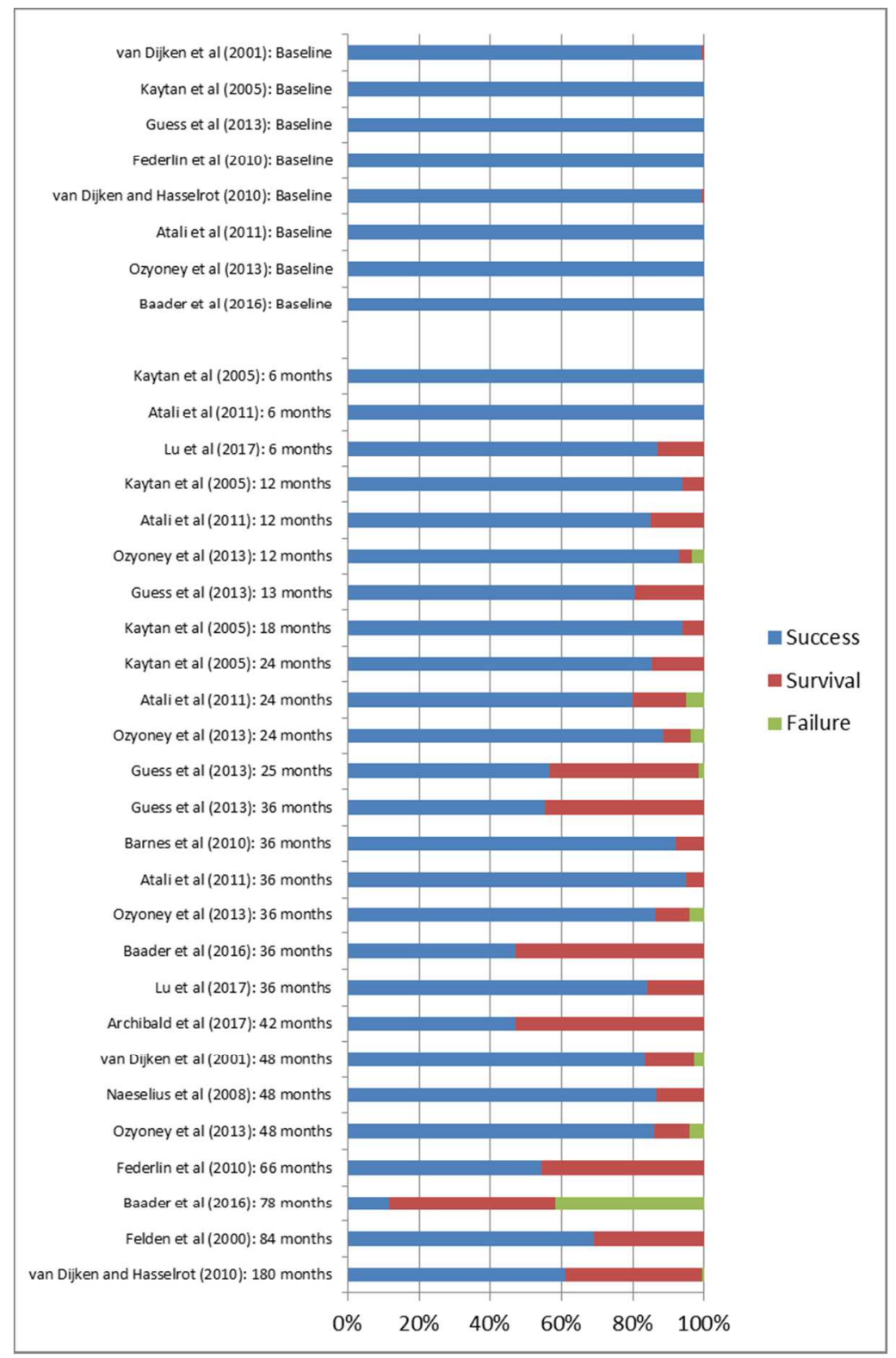

Margin discoloration

$130 \times 200 \mathrm{~mm}(150 \times 150 \mathrm{DPI})$ 


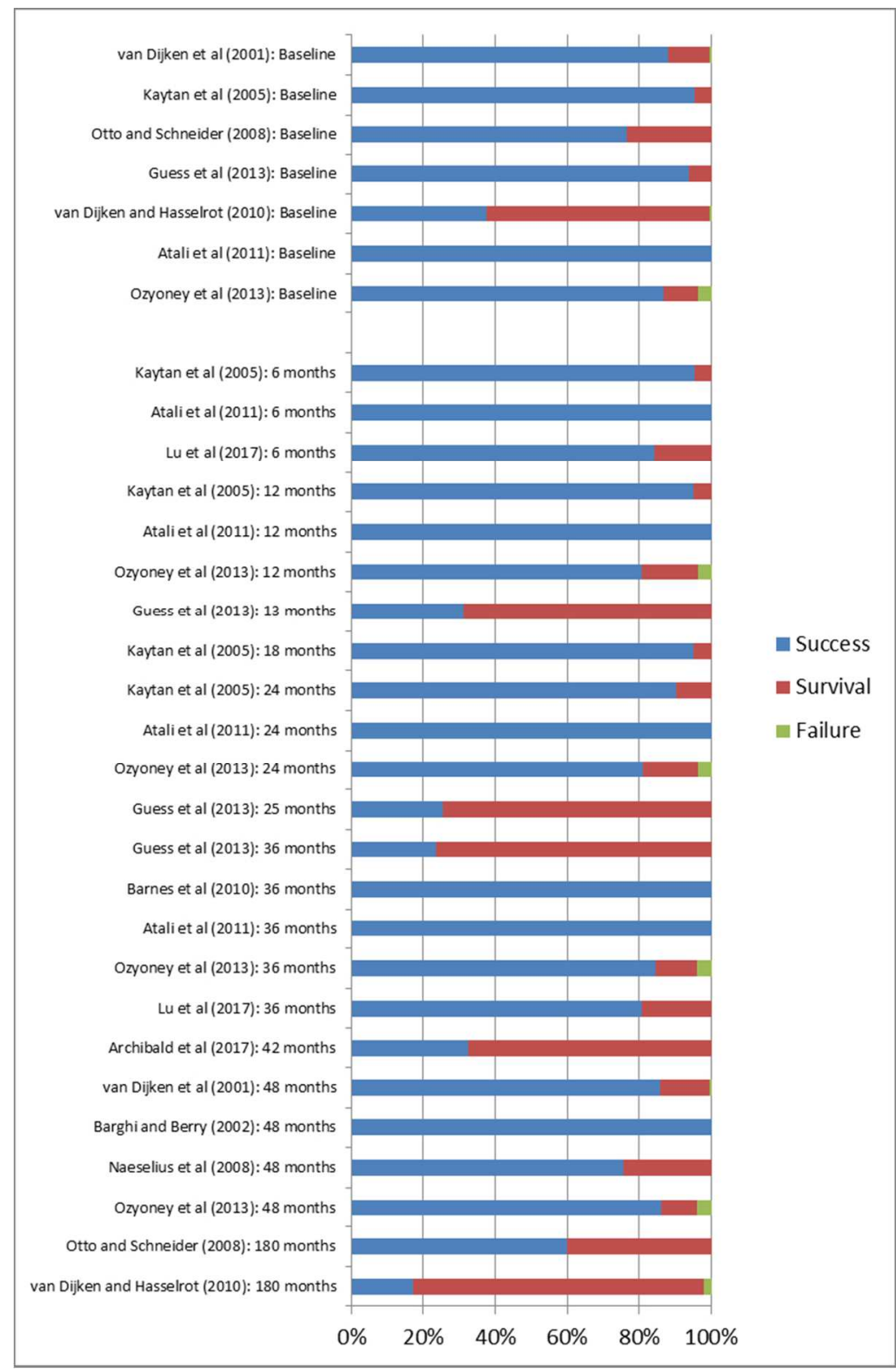

Color match

$130 \times 200 \mathrm{~mm}(150 \times 150 \mathrm{DPI})$

This article is protected by copyright. All rights reserved. 


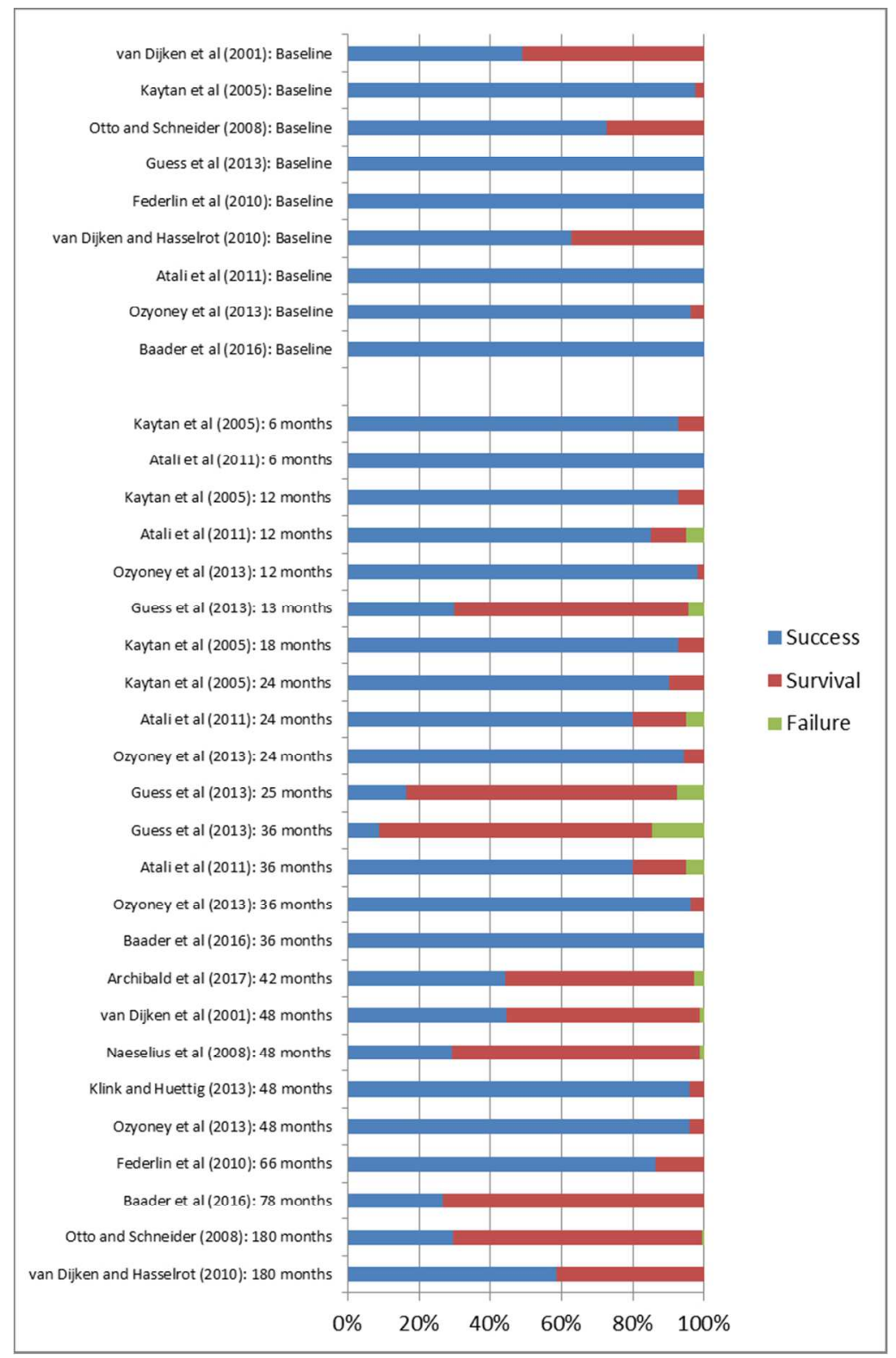

Surface roughness

$130 \times 200 \mathrm{~mm}(150 \times 150 \mathrm{DPI})$ 


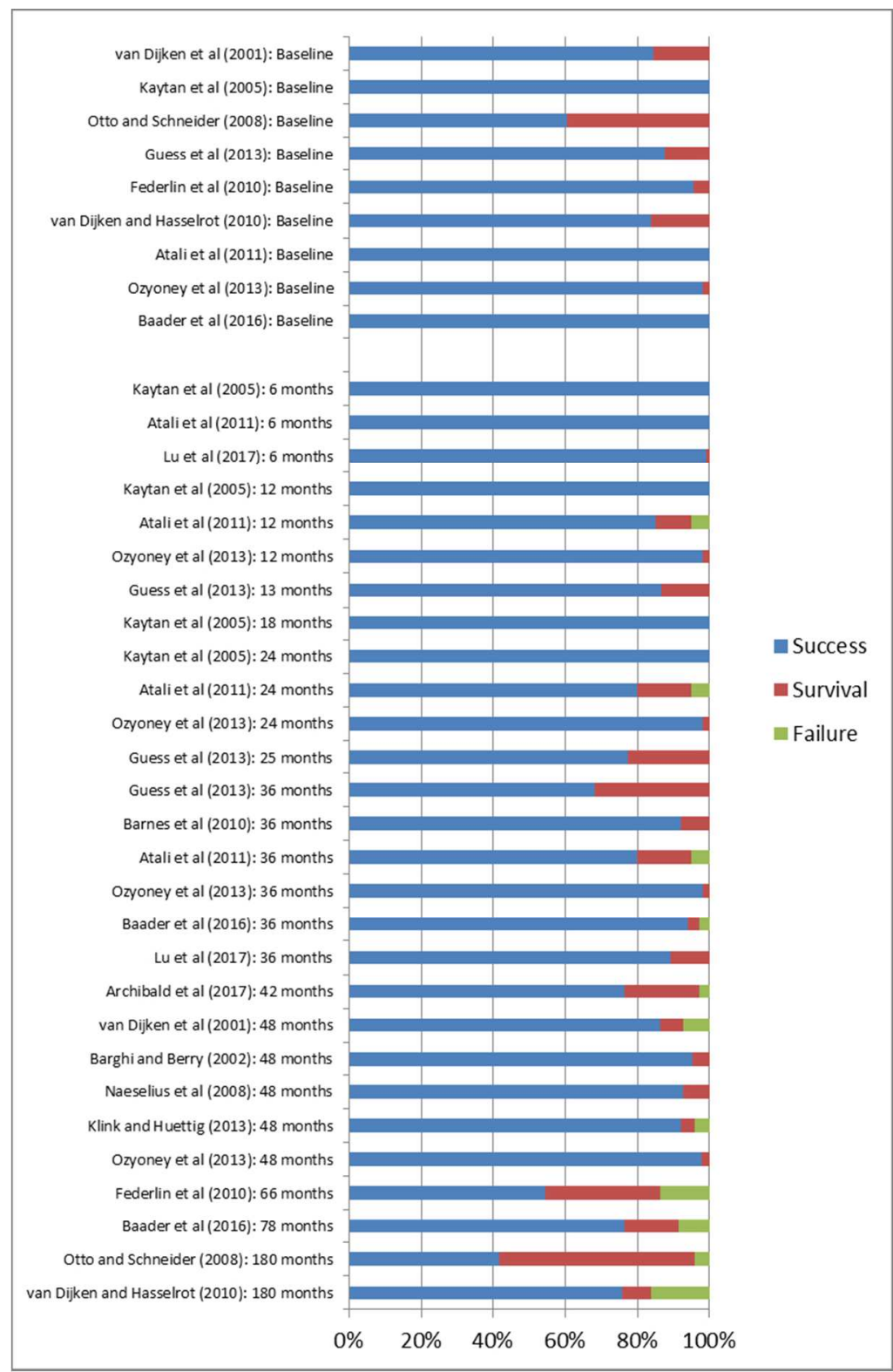

Anatomic form

$130 \times 200 \mathrm{~mm}(150 \times 150$ DPI $)$ 


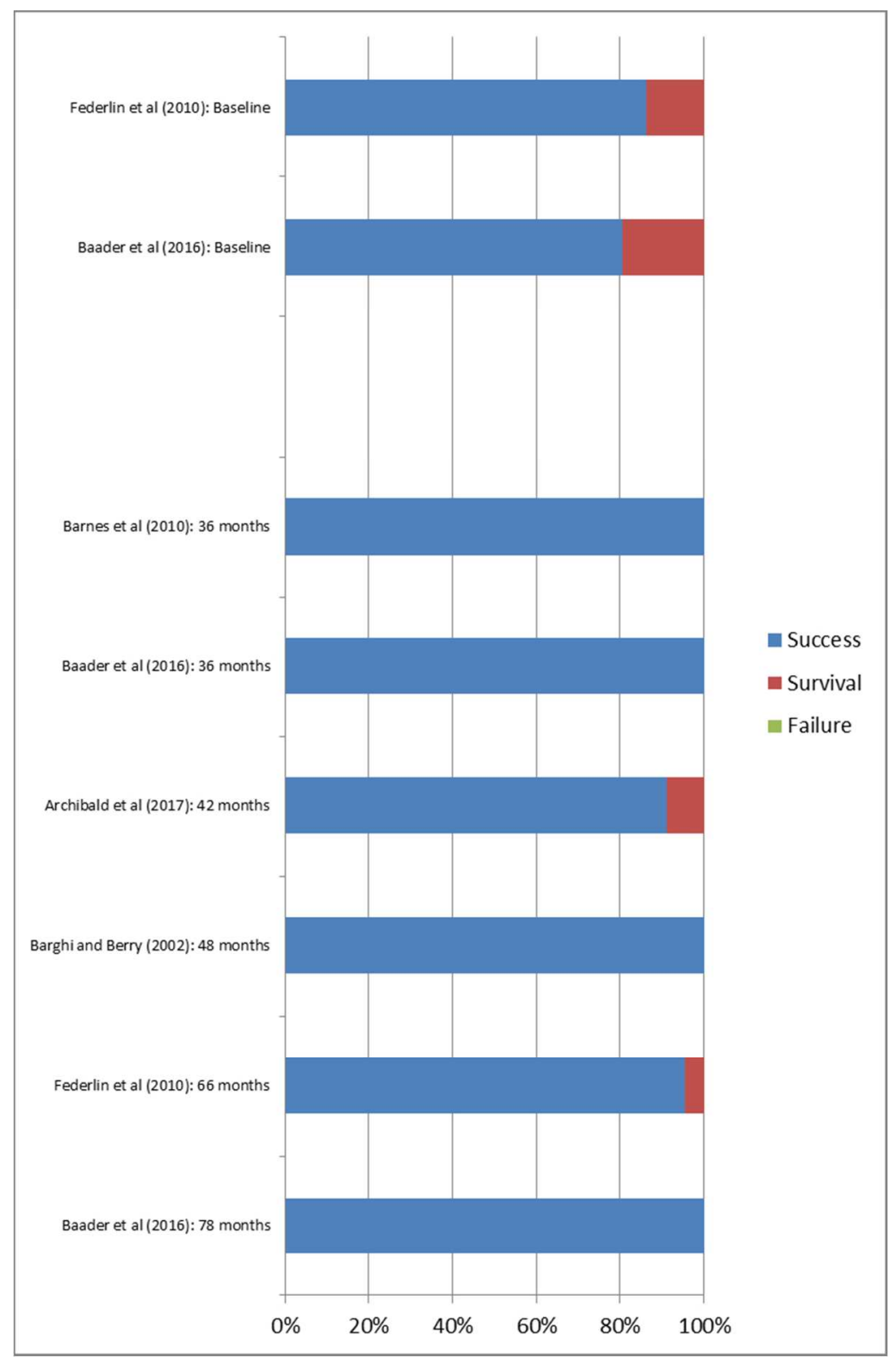

Hypersensitivity

$130 \times 200 \mathrm{~mm}(150 \times 150 \mathrm{DPI})$

This article is protected by copyright. All rights reserved. 
TABLE 1. Inclusion criteria

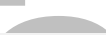

Human clinical study conducted in University, private practice or public clinic setting

Clinical study on ceramic onlay or partial ceramic restoration that covers one cusp up to all cusps

Peer-reviewed journal article

Adult participants

Study that clearly outlined the outcome of ceramic onlays

Retrospective or prospective study

At least, 2 years duration study

English language study
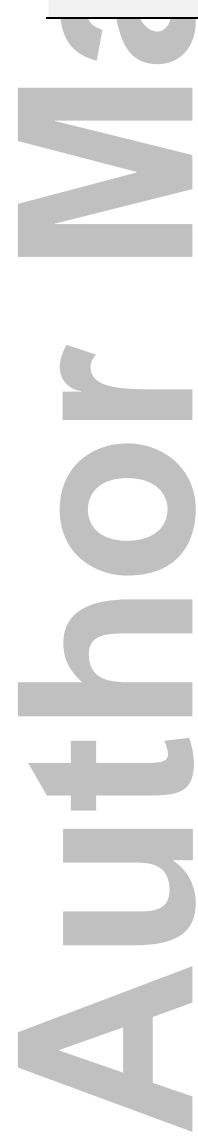
TABLE 2. Critical Appraisal Skills Programme (CASP) guidelines and scoring system

\section{CASP guidelines}

1 Did the study address a clearly focused issue?

2 Was the cohort recruited in an acceptable way?

3 Was the exposure accurately measured to minimise bias?

$4 \quad$ Was the outcome accurately measured to minimise bias?

$5 \quad$ Have the authors identified all important confounding factors?

6 Have the authors taken account of confounding factors in the design and/or analysis?

$7 \quad$ What are the results of the study? (Are they clear?)

8 How precise are the results?

$9 \quad$ Do you believe the results?

10 Can the results be applied to the local population?

11 Do the results of the study fit with other available evidence?

12 What are the implications of this study for practice? (Is the study

Yes (1) - No/Unclear (0)

\section{Score}

Yes (1) - No/Unclear (0)

Yes (1) - No/Unclear (0)
Yes (1) - No/Unclear (0)

Yes (1) - No/Unclear (0)

Yes (1) - No/Unclear (0)

Yes (1) - No/Unclear (0)

Yes (1) - No/Unclear (0)

Yes (1) - No/Unclear (0)

Yes (1) - No/Unclear (0)

Yes (1) - No/Unclear (0) clinically relevant?) 
TABLE 3. The excluded studies and the reasons of their exclusion

T.r.
Study (year)
Reason of exclusion

Kramer et al. (1999)

Reported the combined outcome of inlay and onlay restorations

Frankenberger et al. (2000) $\quad$ Reported the combined outcome of inlay and onlay restorations

Posselt and Kerschbaum Reported the combined outcome of inlay and onlay restorations

$(2003)^{32}$

Schulte et al. (2005) $\quad$ Reported the combined outcome of inlay and onlay restorations

Federlin et al. (2006) $\quad$ Earlier study of an included paper by the same research group ${ }^{52}$

Federlin et al. $(2007)^{25} \quad$ Earlier study of an included paper by the same research group ${ }^{52}$

Frankenberger et al. $(2008)^{28} \quad$ Reported the combined outcome of inlay and onlay restorations

Kramer et al. (2008) $\quad$ Reported the combined outcome of inlay and onlay restorations

Zimmer et al. (2008) $\quad$ Reported the combined outcome of inlay and onlay restorations

Guess et al. (2009) $\quad$ Earlier study of an included paper by the same research group ${ }^{55}$

Silva et al. (2009) $\quad$ Reported the combined outcome of inlay and onlay restorations

Tagtekin et al. (2009) $\quad$ Reported the combined outcome of inlay and onlay restorations

Schenke et al. $(2010)^{35} \quad$ Earlier study of an included paper by the same research group ${ }^{58}$

Schenke et al. (2012) $\quad$ Earlier study of an included paper by the same research group ${ }^{58}$

Santos et al. (2013) $\quad$ Reported the combined outcome of inlay and onlay restorations

Federlin et al. (2014) $\quad$ Earlier study of an included paper by the same research group ${ }^{58}$ 


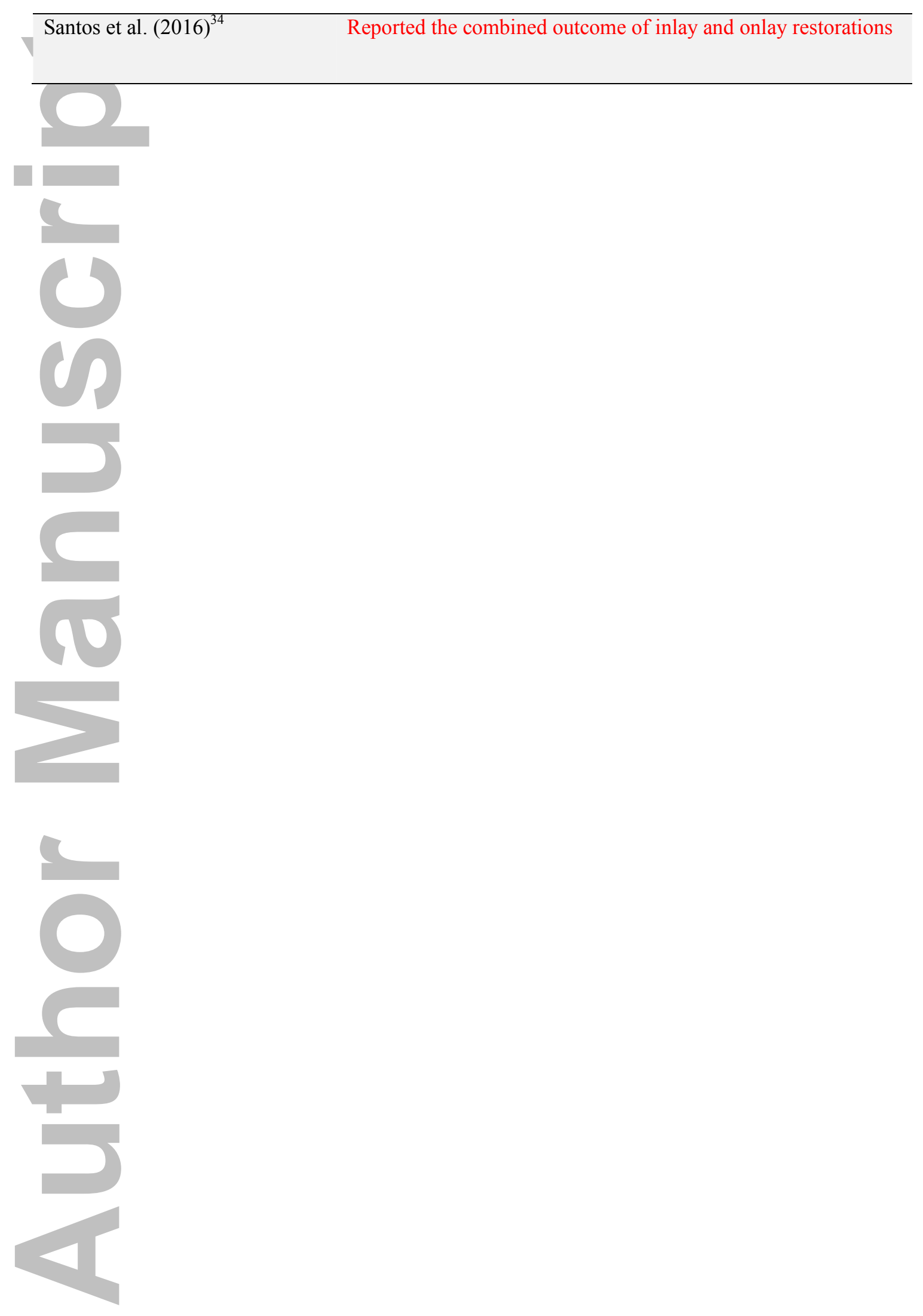




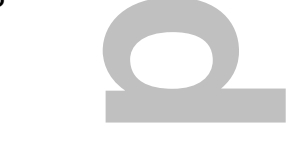

TABLE 4. Summary of the included studies

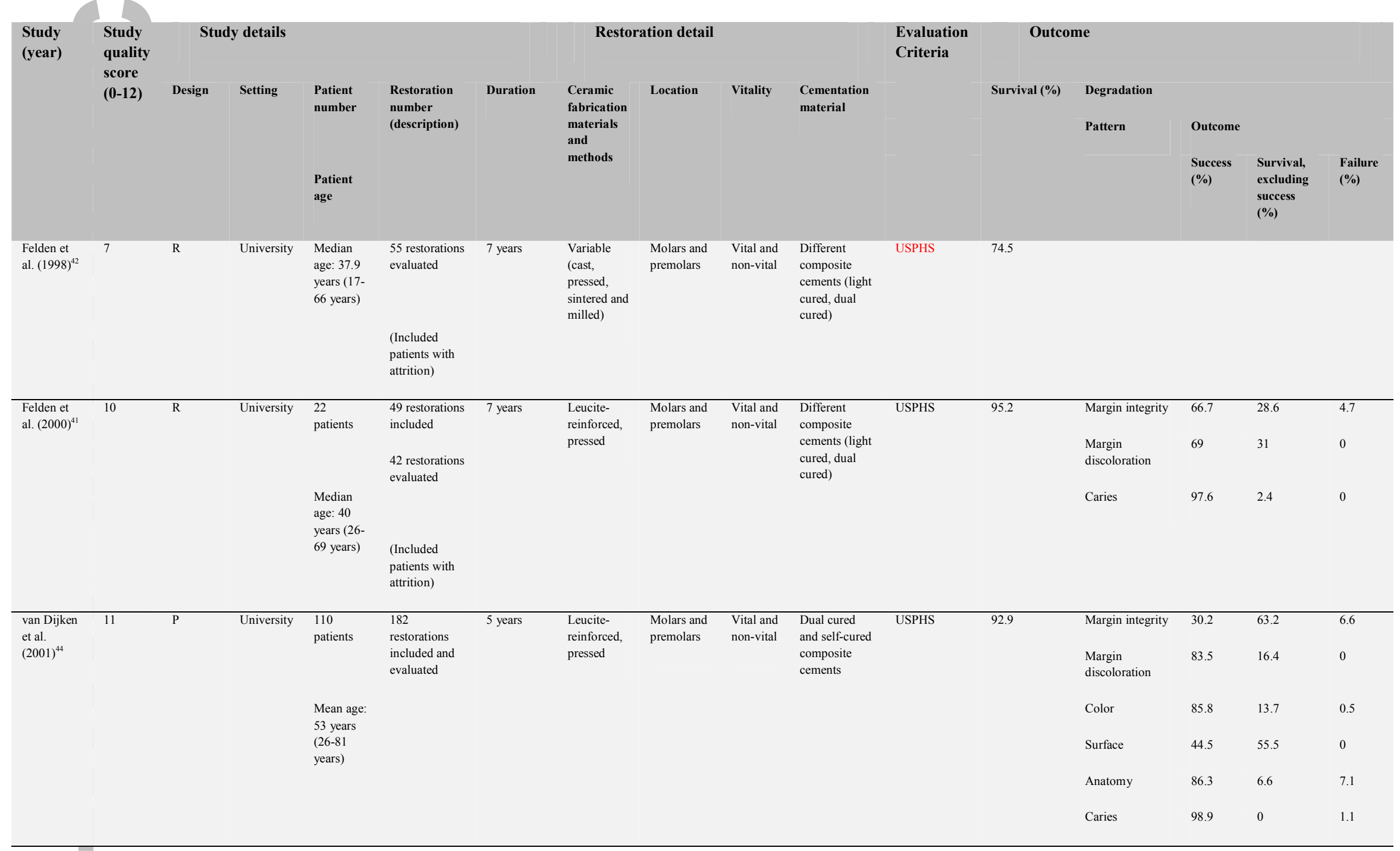




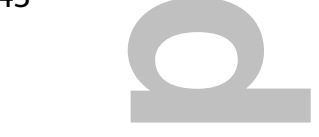

$+$

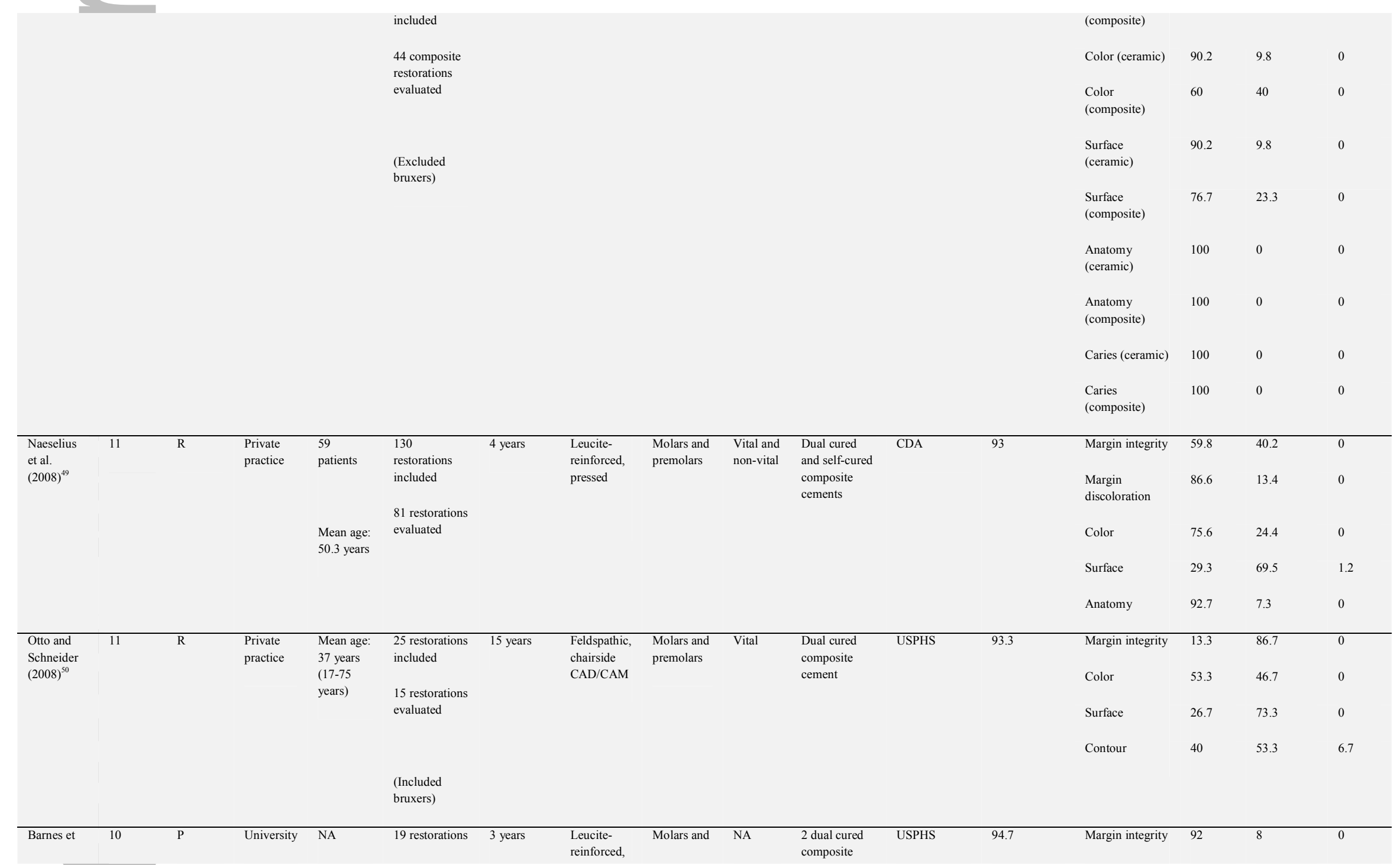




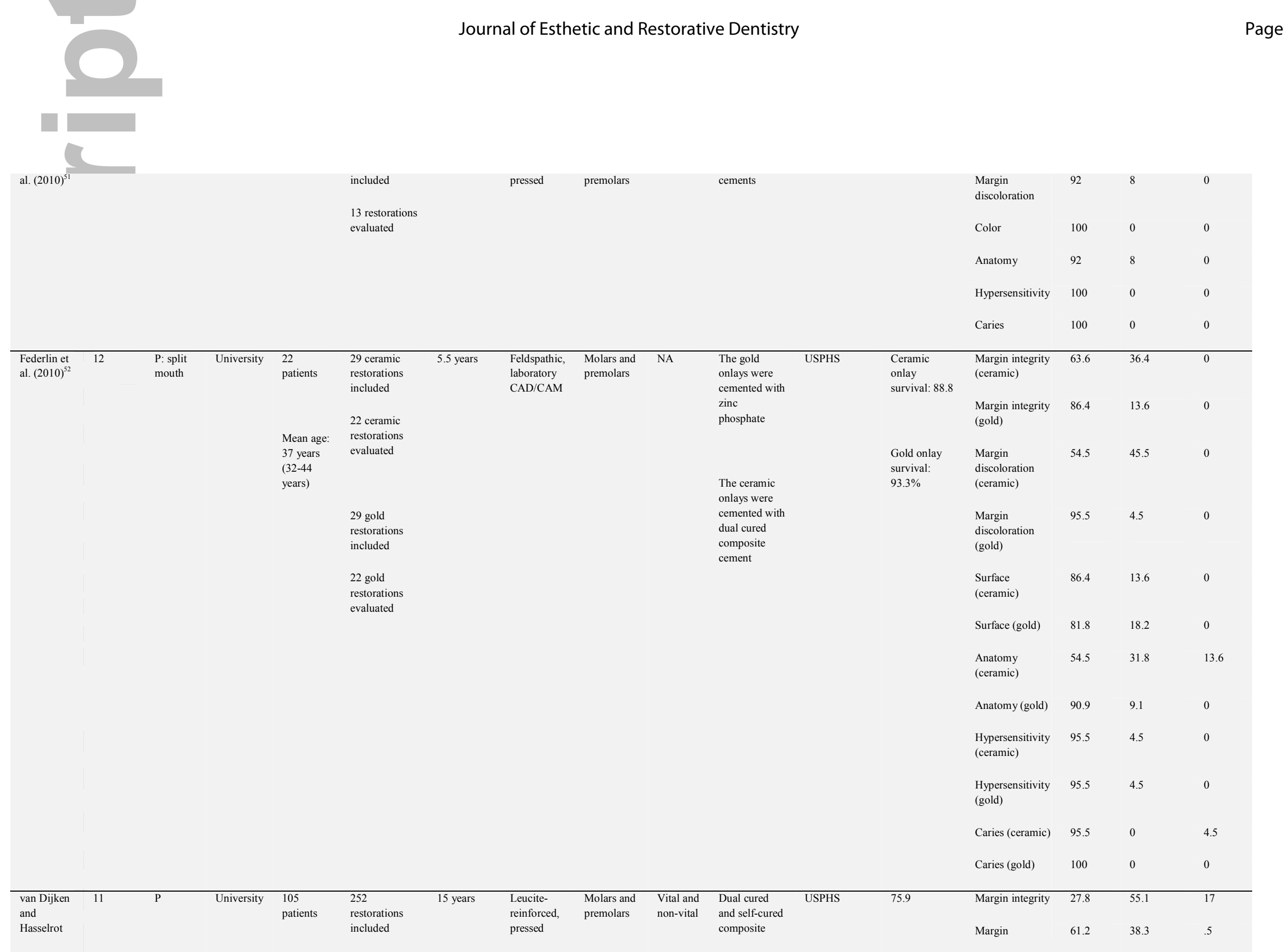




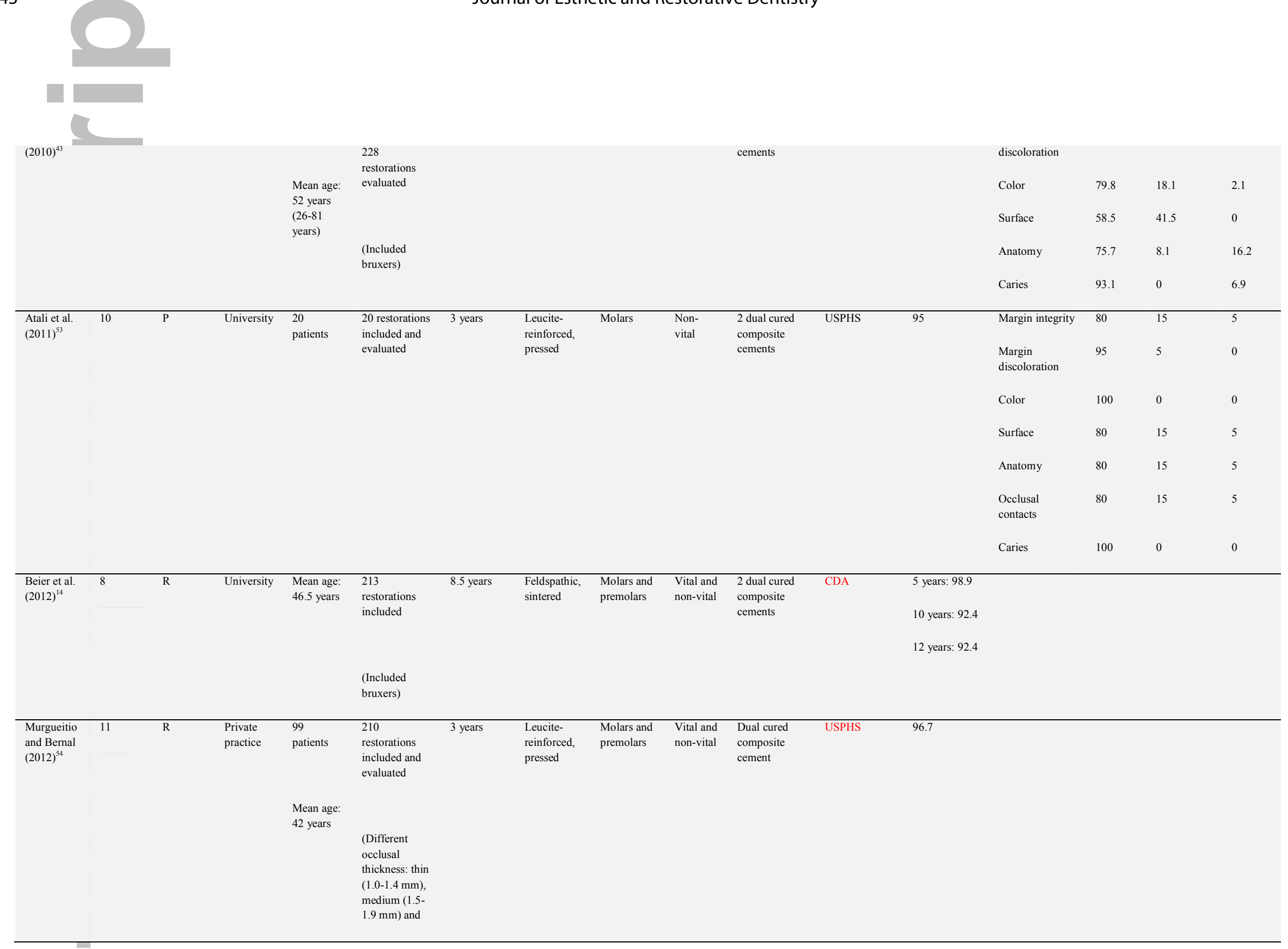

This article is protected by copyright. All rights reserved. 
thick (2 $\mathrm{mm}$ or

more))

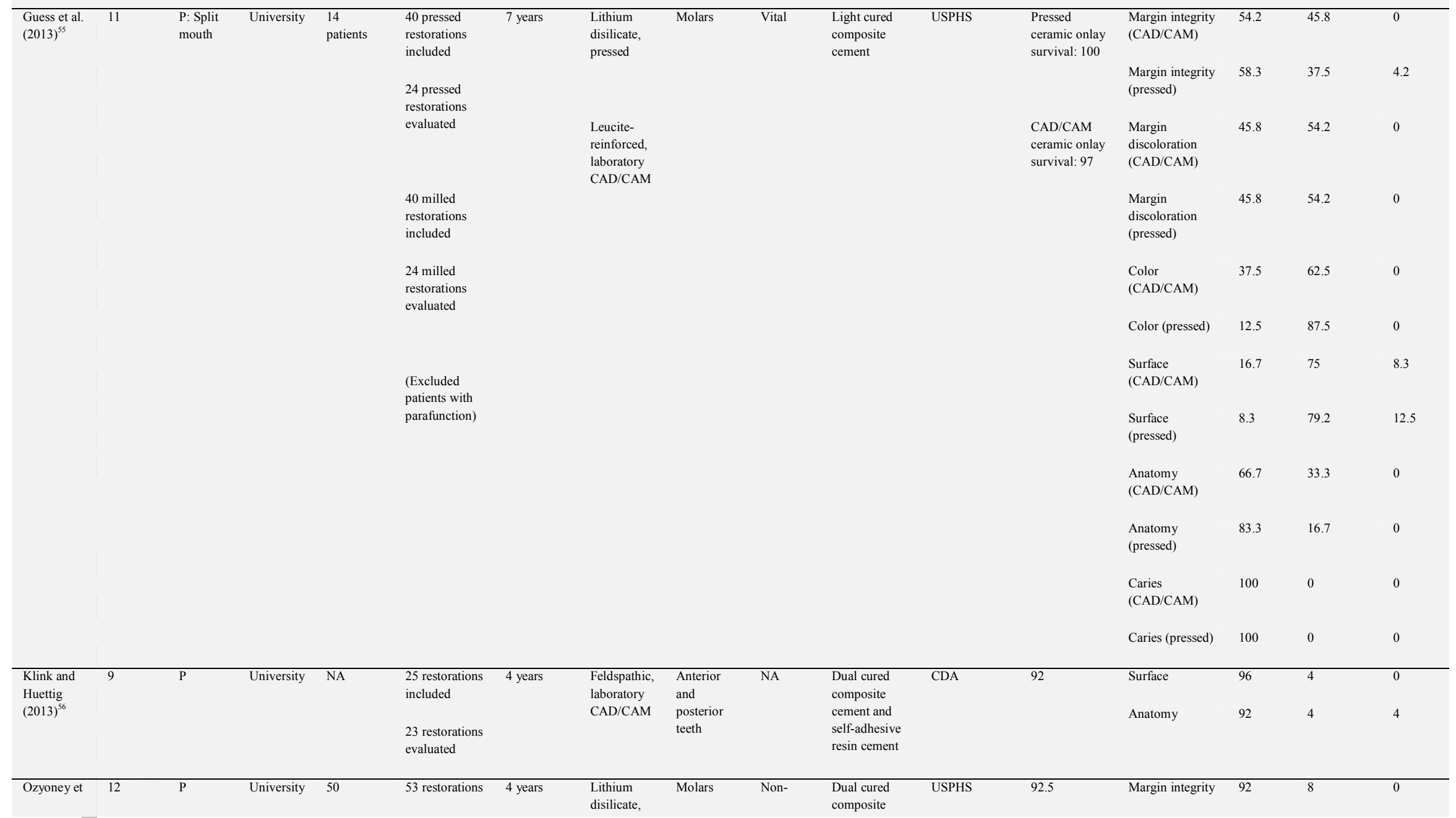

This article is protected by copyright. All rights reserved. 


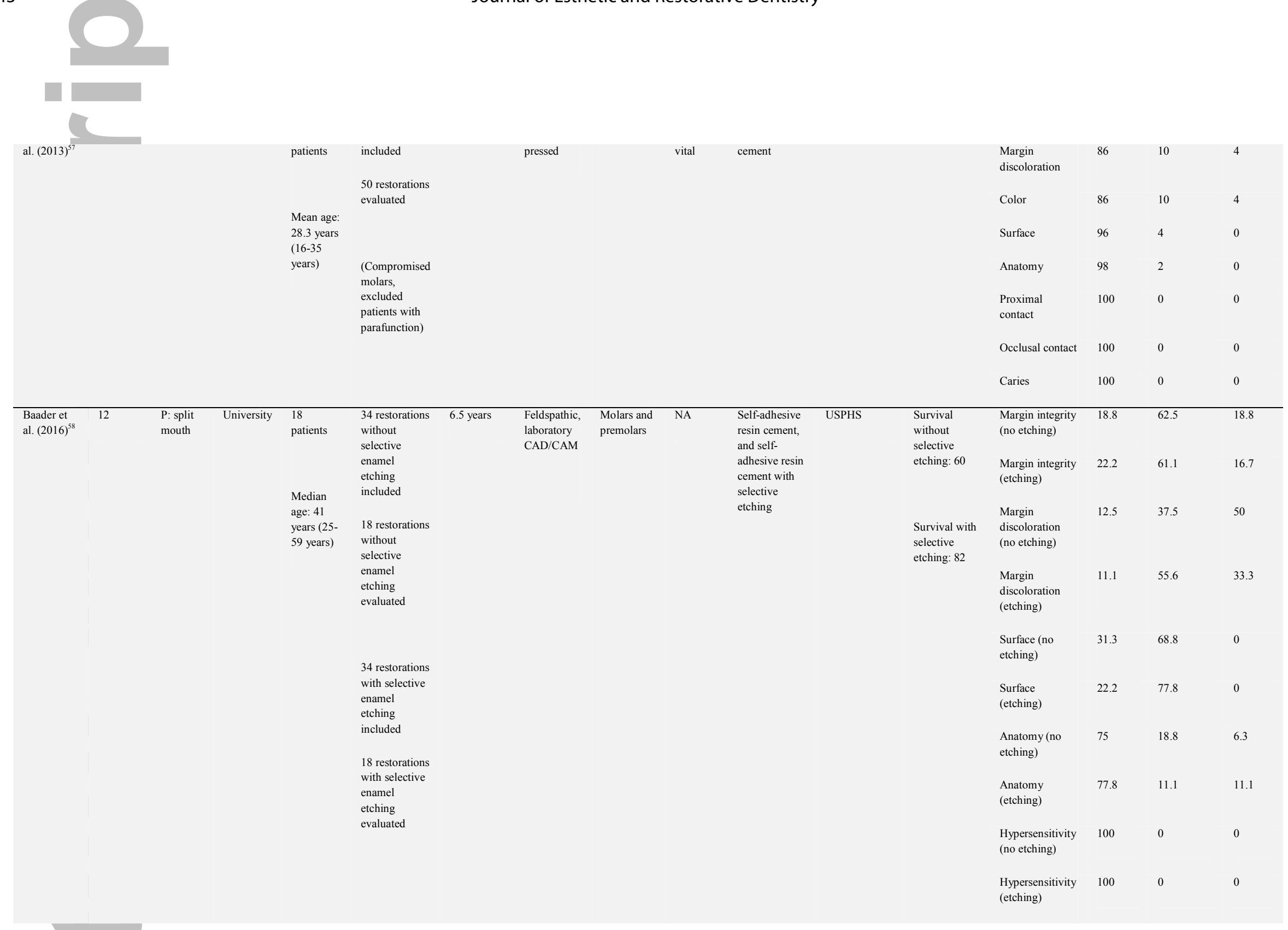


CDA = California Dental Association criteria $; \mathrm{NA}=$ Not available; $\mathrm{PFM}=$ Porcelain fused-to-metal; $\mathrm{P}=$ Prospective; $\mathrm{R}=$ Retrospective; USPHS = United States Public Health Service criteria. 


\section{University Library}

\section{- M M I N E R VA A gateway to Melbourne's research publications}

Minerva Access is the Institutional Repository of The University of Melbourne

Author/s:

Abduo, J;Sambrook, RJ

Title:

Longevity of ceramic onlays: A systematic review

Date:

2018-05-01

Citation:

Abduo, J. \& Sambrook, R. J. (2018). Longevity of ceramic onlays: A systematic review. JOURNAL OF ESTHETIC AND RESTORATIVE DENTISTRY, 30 (3), pp.193-215. https:// doi.org/10.1111/jerd.12384.

Persistent Link:

http://hdl.handle.net/11343/283887 